\title{
Configurações
}

Revista de sociologia

\section{Representações sociais do processo colonial - perspetivas cruzadas entre estudantes moçambicanos e portugueses}

Social representations of the colonial process - Differing perspectives of

Mozambican and Portuguese students

Représentations sociales du processus colonial - Regards croisés entre étudiants mozambicains et portugais ${ }^{\text {涪 }}$

\section{Rosa Cabecinhas e João Feijó}

\section{OpenEdition}

\section{Journals}

Edição electrónica

URL: http://journals.openedition.org/configuracoes/2053

DOI: 10.4000/configuracoes.2053

ISSN: 2182-7419

\section{Editora}

Centro de Investigação em Ciências Sociais

Edição impressa

Data de publição: 1 Dezembro 2013

Paginação: 117-139

ISBN: 1646-5075

ISSN: $1646-5075$

\section{Refêrencia eletrónica}

Rosa Cabecinhas e João Feijó, «Representações sociais do processo colonial -perspetivas cruzadas entre estudantes moçambicanos e portugueses », Configurações [Online], 12 | 2013, posto online no dia 08 outubro 2014, consultado o 30 abril 2019. URL : http://journals.openedition.org/ configuracoes/2053; DOI : 10.4000/configuracoes.2053 


\title{
Representações sociais do processo colonial -perspetivas cruzadas entre estudantes moçambicanos e portugueses
}

\author{
Social representations of the colonial process - Differing perspectives of \\ Mozambican and Portuguese students \\ Représentations sociales du processus colonial - Regards croisés entre étudiants

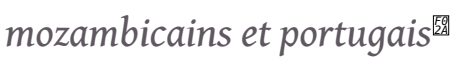

Rosa Cabecinhas and João Feijó

\section{Introdução}

1 As narrativas da história "universal" veiculadas pelos média e disseminadas nas enciclopédias ditas globais são talvez um dos mais evidentes exemplos do quanto ainda há a fazer para descolonizar o conhecimento. Nessas narrativas, fortemente ancoradas num pensamento hegemónico europeu, o "Norte" é representado como o motor da história "universal", sendo o "Sul" remetido ao esquecimento. O silenciamento do "Sul" é particularmente evidente na forma como tem sido contada a história da "expansão europeia", cujos efeitos se fazem sentir aos mais diversos níveis.

2 Na opinião de Alfredo Margarido, "o discurso lusófilo actual limita-se a procurar dissimular, mas não a eliminar, os traços brutais do passado" (2000: 76). $O$ autor considera que a invenção da lusofonia ${ }^{1}$ se fez através de uma amnésia coletiva em relação à violência que foi exercida sobre os povos que hoje falam português.

3 Na mesma linha de ideias, Nataniel Ngomane (2012) denuncia a versão lusocêntrica da história que foi forçado a aprender na escola durante o período do Estado Novo, em Moçambique, onde se ensinava sobre os heróis portugueses, mas nada sobre os heróis 
moçambicanos. Nesse sentido, pergunta ironicamente: "Lusofonia: quem quer ser apagado?" (2012: 24). Ngomane denuncia também a violência implícita do termo "expressão portuguesa" que contribui para um apagamento e esvaziamento identitário. Nas palavras do autor, "[a]plicar essa expressão a indivíduos, povos, países e outras entidades não portuguesas, equivale a atribuir - e de maneira matreira! -, qualidades ou características portuguesas a entidades que, não sendo portuguesas, acabam por ter-e-ver apagadas e esvaziadas as suas próprias qualidades ou características" (Ngomane, 2012: 24).

4 Ora, ninguém quer ser apagado nem reduzido a uma expressão homogeneizante e redutora, que não dá conta da heterogeneidade do denominado espaço lusófono. Assim, urge dar voz a diferentes narrativas sobre a história, de modo a tornar visíveis as versões de pessoas e grupos que foram sistematicamente "apagados" da história durante o período colonial e que continuam, muitas vezes, invisíveis nas narrativas históricas dominantes em período dito pós-colonial (Cabecinhas, 2011). Parafraseando as palavras de Mia Couto, urge descolonizarmo-nos uns aos outros e esperamos que este artigo, ao analisar criticamente as representações sociais da história, contribua de alguma forma para a descolonização do pensamento.

\section{Narrativa, memória e identidade}

5 A memória coletiva desempenha um papel essencial na criação e manutenção da identidade social (Licata et al., 2007; Liu \& Hilton, 2005). Proporciona um "passado utilizável", que pode servir para promover as reivindicações identitárias do presente (Wertsch, 2002: 76), tratando-se assim de um processo ativo, seletivo, estratégico e, portanto, dinâmico. Na opinião de Wertsch (2002), a memória coletiva é mediada por recursos textuais, que não são neutros, uma vez que trazem com eles uma posição social e perspetiva.

6 Na mesma linha de pensamento, Luís Cunha considera que as imagens do passado tendem a legitimar a ordem social do presente. No entanto, simultaneamente, existem expressões que contestam essa ordem. Assim, a memória social pode ser entendida "como um campo de disputa, passando o controlo social e mesmo o exercício do poder, pela capacidade de definir o memorável e o que deve ser esquecido" (Cunha, 2006: 86).

7 As identidades e as representações sociais da história encontram-se em constante interação, uma vez que as representações estão relacionadas com os processos de construção da identidade grupal, assumindo um papel indicativo sobre as formas possíveis de relacionamento com outros grupos, bem como sobre as opções para enfrentar os desafios do presente (Liu e Hilton, 2005).

Embora se tenha verificado na última década um incremento dos estudos sobre memória social, continuam a ser muito escassos os estudos comparativos sobre a memória histórica em contexto pós-colonial nos países de língua oficial portuguesa. No caso da relação Portugal-Brasil, foram efetuados diversos estudos sobre as "memórias dos descobrimentos" por ocasião das comemorações dos "500 anos do descobrimento do Brasil", por uma equipa de investigadores brasileiros e portugueses. Por exemplo, Möller, Sá e Bezzera (2004) demonstraram que os brasileiros atribuem alguns méritos à colonização, mas reconhecem em maior grau os seus aspetos negativos do que os portugueses. Por seu turno, Vala e Saint-Maurice (2004), numa análise das representações 
sociais do processo de colonização e dos atores envolvidos, demonstraram que a representação brasileira é mais negativa, ao passo que a portuguesa corresponde a uma "idealização da colonização" que se traduz num silenciamento dos seus aspetos negativos. Assim, o mito do luso-tropicalismo (Freyre, 1933) parece continuar a estruturar as representações do passado colonial em Portugal, influenciando também as auto- e heterorrepresentações identitárias (Cabecinhas, 2007; Vala, 2013; Valentim, 2011). Diversos estudos empíricos apontam para a importância atribuída pelos portugueses à sua história e ao seu passado "glorioso" (e.g., Miranda, 2002; Sobral, 2010). As grandes navegações e os "descobrimentos" continuam a ser considerados como a "idade de ouro" da história nacional, o que contribui para silenciar os efeitos mais brutais da expansão colonial (Sobral, 2010).

Na mesma linha de ideias, Bernd Reiter considera que "o legado do colonialismo ainda influencia fortemente as formas pelas quais Portugal define a sua pertença nacional" (2005: 89). Reiter considera que o facto de Portugal ocupar uma posição ambivalente na hierarquia internacional contribui para uma dupla tensão: "Por um lado, o orgulho nacional, prejudicado por comparações potencialmente humilhantes com as mais ricas e mais poderosas nações da Europa, exige a evocação do passado 'glorioso' de Portugal" ( ibid.). Mas, segundo o autor, essa distância em relação a alguns aspetos daquele passado também é necessária: "O resultado é uma espécie de neurose portuguesa sobre o seu passado colonial" (ibid.: 87).

10 A retórica da lusofonia assume frequentemente a forma de "nostalgia imperial" (Lourenço, 2001; Martins, 2006), contribuindo para conflitos e desentendimentos, tanto nas relações interpessoais como em assuntos internacionais.

11 Um exemplo recente é a forma como a história dos descobrimentos ${ }^{2}$ é convocada para justificar um posicionamento desfavorável face ao novo Acordo Ortográfico da Língua Portuguesa por parte dos jovens portugueses (Carvalho e Cabecinhas, 2013).

12 Neste artigo apresentamos os resultados de estudos realizados em Moçambique e em Portugal sobre as representações sociais da história nacional (Estudo 1) e as representações do período colonial, as atitudes face à colonização e as suas possíveis implicações nas relações pós-coloniais (Estudo 2). Parte dos dados foram previamente apresentados em trabalhos anteriores, sendo aqui integrados com novos dados e analisados de forma comparativa. Em ambos os países foram aplicados questionários redigidos em língua portuguesa. Em Portugal todos os inquiridos declararam como língua materna o português.

13 Em contrapartida, em Moçambique verificou-se uma grande diversidade de línguas maternas - apenas $31,1 \%$ dos participantes declararam o português como língua materna, pelo que a grande maioria dos participantes o utiliza como segunda língua. Nenhum dos inquiridos manifestou qualquer dificuldade na compreensão das questões e todos responderam em português, pelo que consideramos que a língua usada no questionário não afetou a qualidade das respostas dos inquiridos.

Ao comparar as respostas dos participantes moçambicanos e portugueses, não pretendemos generalizar os resultados à população dos respetivos países, mas apenas abordar de forma exploratória o impacto das pertenças nacionais nas representações da história. Todos os grupos nacionais são heterogéneos, sendo constituídos por uma grande diversidade de indivíduos, com diferentes percursos e experiências de vida e pertencendo a grupos com diferentes posicionamentos na estrutura social. 
O foco nos jovens e não na população em geral deveu-se ao facto de pretendermos estudar as representações de pessoas nascidas após o 25 de Abril de 1974. O facto de as amostras serem constituídas exclusivamente por estudantes universitários deveu-se, por um lado, a questões de exequibilidade na aplicação dos questionários em boas condições e, por outro lado, a questões de comparabilidade com os estudos realizados noutros países.

\section{Estudo 1: Representações sociais da história nacional}

O objetivo deste estudo foi analisar as representações sociais da história construídas por jovens moçambicanos e jovens portugueses. No total foram inquiridos 298 estudantes, 180 moçambicanos e 118 portugueses.

17 Os estudantes foram convidados a participar num estudo internacional sobre história, sendo-lhes explicado que o que interessava era a sua opinião pessoal sobre a história e não o seu nível de conhecimentos. No que respeita à história nacional, pedia-se aos participantes para listarem os cinco acontecimentos que consideravam mais relevantes na história do seu país (Moçambique ou Portugal, conforme o local de recolha de dados). Uma vez efetuada a listagem, os participantes deveriam avaliar o impacto de cada um desses acontecimentos na história nacional e posteriormente indicar as emoções que associavam a cada acontecimento. A evocação de acontecimentos era efetuada de forma completamente livre, já que não era fornecida qualquer listagem prévia aos participantes. As emoções associadas aos acontecimentos foram também recolhidas de forma aberta. Já os níveis de impacto dos acontecimentos foram medidos através de escalas fechadas (1=muito negativo; $7=$ =muito positivo).

Os dados relativos aos acontecimentos da história nacional foram previamente analisados por Cabecinhas e Feijó (2010). No âmbito deste artigo revisitámos alguns desses resultados, focando a análise nos acontecimentos que se prendem com a história que liga ambos os países. Os dados relativos aos acontecimentos da história nacional de cada um dos países são apresentados na Tabela 1, assim como o impacto que lhes é atribuído pelos participantes.

Tabela 1. Acontecimentos da História Nacional 


\begin{tabular}{|c|c|c|c|c|c|}
\hline Moçambique & $\%$ & Impacto & Portugal & $\%$ & Impacto \\
\hline $\begin{array}{l}\text { Independência } \\
\text { Nacional }\end{array}$ & 81,67 & $\begin{array}{c}6,8 \\
(0,92)\end{array}$ & 25 de Abril de 1974 & 80,5 & $\begin{array}{c}6,58 \\
(0,88)\end{array}$ \\
\hline $\begin{array}{l}\text { Acordo Geral de } \\
\text { Paz }\end{array}$ & 43,89 & $\begin{array}{c}6,74 \\
(1,08)\end{array}$ & Descobrimentos & 79,7 & $\begin{array}{c}6,41 \\
(1,13)\end{array}$ \\
\hline $\begin{array}{l}\text { Guerra de } \\
\text { resistência }\end{array}$ & 36,11 & $\begin{array}{c}6,35 \\
(1,57)\end{array}$ & $\begin{array}{l}\text { Implantação da } \\
\text { República }\end{array}$ & 41,5 & $\begin{array}{c}6,02 \\
(1,01)\end{array}$ \\
\hline $\begin{array}{l}\text { Guerra Civil / } \\
\text { Guerra de } \\
\text { destabilização }\end{array}$ & 32,22 & $\begin{array}{c}1,89 \\
(1,84)\end{array}$ & $\begin{array}{l}\text { Adesão à União } \\
\text { Europeia }\end{array}$ & 36,4 & $\begin{array}{l}6,00 \\
(0,9)\end{array}$ \\
\hline Colonização & 28,33 & $\begin{array}{l}2,75 \\
(2,18)\end{array}$ & $\begin{array}{l}\text { Salazarismo/Estado } \\
\text { Novo }\end{array}$ & 29,66 & $\begin{array}{c}2,15 \\
(1,26)\end{array}$ \\
\hline $\begin{array}{l}\text { Democracia / } \\
\text { Multipartidarismo }\end{array}$ & 22,78 & $\begin{array}{c}6,18 \\
(1,41)\end{array}$ & Fundação & 20,3 & $\begin{array}{c}6,75 \\
(0,43)\end{array}$ \\
\hline $\begin{array}{l}\text { Morte de Samora } \\
\text { Machel }\end{array}$ & 20 & $\begin{array}{c}1,79 \\
(1,62)\end{array}$ & Colonialismo & 16,1 & $\begin{array}{c}2,18 \\
(1,11)\end{array}$ \\
\hline $\begin{array}{l}\text { Primeiras eleições } \\
\text { gerais }\end{array}$ & 17,78 & $\begin{array}{c}6,45 \\
(1,38)\end{array}$ & Descolonização & 16,1 & $\begin{array}{c}3,53 \\
(2,03)\end{array}$ \\
\hline Acordos de Lusaca & 15 & $\begin{array}{c}5,5 \\
(2,40)\end{array}$ & Restauração & 11 & $\begin{array}{c}6,75 \\
(0,43)\end{array}$ \\
\hline $\begin{array}{l}\text { Reversão de Cahora } \\
\text { Bassa }\end{array}$ & 14,44 & $\begin{array}{c}6,16 \\
(1,54)\end{array}$ & Guerra Colonial & 10,2 & $\begin{array}{c}1,27 \\
(0,45)\end{array}$ \\
\hline
\end{tabular}

Legenda:

\% = percentagem de evocação espontânea de determinado acontecimento da história nacional Impacto = Média (M) e Desvio-padrão (DP); Escala de impacto: 1 = muito negativo; 7 = muito positivo Fonte: Cabecinhas \& Feijó (2010)

19 Como podemos constatar, os acontecimentos que assinalam a independência nacional assumem uma importância preponderante em ambos os países. Mas essa importância é especialmente evidente no caso dos participantes moçambicanos, já que $81,67 \%$ dos inquiridos mencionaram espontaneamente a independência nacional (proclamada a 25 de Junho de 1975 pelo Presidente Samora Machel), sendo esse acontecimento não só o mais evocado, mas também o que é avaliado de forma mais positiva $(M=6,8)$.

Os participantes portugueses não referem explicitamente a expressão "independência nacional", mas mencionam os dois acontecimentos que sinalizam a independência: a fundação do Estado português, protagonizada por D. Afonso Henriques em 1143 (20,3\%), e a Restauração da independência, quando Portugal recuperou a independência, após sessenta anos de domínio espanhol, em 1640 (11\%).

21 Comparativamente com os congéneres portugueses, na representação da história dos seus países, o momento de formação do Estado independente foi bem mais destacado pelos participantes moçambicanos. Neste caso, quanto mais recente a conquista dessa independência, como no caso de Moçambique, maior a percentagem de evocação espontânea desse acontecimento.

Um dos aspetos em que os dados divergem claramente nos dois países diz respeito aos acontecimentos relacionados com os descobrimentos, o colonialismo e a descolonização. Os participantes portugueses colocaram os "descobrimentos" como um dos acontecimentos mais importantes da história do seu país $(79,7 \%)$, só superado em termos de nomeações espontâneas pelo 25 de Abril de 1974 (80,5\%), sendo ambos os acontecimentos considerados muito positivos pelos participantes. Tratando-se de um 
acontecimento bastante remoto, a elevada saliência dos descobrimentos deve-se ao facto de este ser constantemente reatualizado nos manuais escolares e nos média.

Em contrapartida, nenhum participante moçambicano mencionou espontaneamente a expressão "descobrimentos" ao pensar na história de Moçambique. A "chegada dos portugueses" foi referida por 3,3\% dos participantes moçambicanos e a "chegada de Vasco da Gama" por 2,2\%; ambos os acontecimentos foram considerados positivos pelos poucos participantes que os evocaram espontaneamente (respetivamente, $M=6,33$ e $M=6,75)$ ). Por seu turno, o "colonialismo" foi evocado por $28,33 \%$ dos participantes moçambicanos e foi considerado por estes como sendo um acontecimento negativo $(\mathrm{M}=2,75)$.

Os acontecimentos relativos ao colonialismo $(16,1 \%)$ e ao processo de descolonização $(16,1 \%)$ assumem grande importância nas evocações dos participantes portugueses. Contrariamente aos descobrimentos, cujo impacto na história nacional é considerado consensualmente positivo $(M=6,41)$, o colonialismo é avaliado negativamente $(M=2,18)$. Por seu turno, a "descolonização" afigura-se como o acontecimento mais polémico, uma vez que as opiniões sobre a sua valência cobrem todo o espectro da escala, desde as mais positivas às mais negativas, o que dá origem a uma média que, embora negativa, pouco se distancia do ponto neutro da escala $(M=3,53)$. Estes resultados merecem ser explicados à luz do "regresso" traumático de cerca de meio milhão de portugueses à antiga metrópole, na sequência dos processos de descolonização, gerador inclusive de clivagens na sociedade portuguesa em resultado dos respetivos processos de integração socioprofissional. Apesar de os participantes terem nascido após esse período, as memórias familiares desse processo terão exercido influência nas atuais representações da história.

A guerra colonial foi considerada o acontecimento mais negativo $(10,2 \% ; M=1,27)$ da história nacional pelos participantes portugueses, suscitando emoções fortemente negativas. Em contrapartida, a guerra da libertação ou guerra da resistência é um dos acontecimentos considerados mais positivos pelos participantes moçambicanos $(36,11 \%$; $\mathrm{M}=6,35)$. Nenhum participante moçambicano mencionou a "descolonização", dado que se trata de uma expressão que remete para a perspetiva portuguesa sobre o processo que se seguiu à Revolução dos Cravos. Para os moçambicanos, o destaque vai para a "libertação", que é representada pela concretização da independência nacional e, como salientámos acima, foi espontaneamente evocada por quase $82 \%$ dos participantes. As palavras "libertação" e "resistência" assumem assim uma forte função identitária. Num país geograficamente extenso, economicamente desintegrado e marcado pela pluralidade sociocultural (ao nível linguístico, religioso, das estruturas de parentesco e demais tradições), a libertação de um opressor comum constituiu uma forma de reforço da união das populações e de "imaginação" (Anderson, 1991) de uma identidade nacional.

$\mathrm{Na}$ linha do ponto anterior, a reversão de Cahora Bassa foi mencionada por $14,44 \%$ dos participantes moçambicanos, sendo considerada como um acontecimento muito positivo $(M=6,16)$. A assinatura, em novembro de 2005, dos acordos de transferência da barragem para o Estado moçambicano finalizou um longo período de negociações entre Portugal e Moçambique acerca do controlo da barragem, que constitui o maior investimento projetado e concretizado durante o período colonial. 0 evento mereceu uma forte cobertura mediática em Moçambique, politicamente capitalizado pelo Governo de então, fazendo na época renascer um entusiasmo nacionalista.

28 Embora não conste na Tabela 1, que apresenta apenas os dez acontecimentos mais referidos, os participantes moçambicanos mencionaram o tráfico de escravos (11\%) como 
o acontecimento mais negativo da história de Moçambique ( $M=1)$. Verificaram-se ainda algumas referências a fenómenos de trabalho forçado (chibalo). A introdução em Moçambique do estatuto do indigenato e de um regime de trabalho obrigatório não deixa de fazer parte da memória social dos estudantes universitários em análise, sobretudo quando estes são evocados em contexto de discussão de grupo (cf. Feijó \& Cabecinhas, 2009). De acordo com Hedges (1999), no período após a II Guerra Mundial verificou-se uma extensão e intensificação daquele sistema de recrutamento, sobretudo nas plantações de algodão no Norte do país. Este sistema de recrutamento de trabalhadores perdurou até 1961, quando, em função de uma série de pressões internacionais, Portugal aboliu o Estatuto do Indigenato, revogando todo um corpo de legislação laboral específico, para pessoas anteriormente designadas de indígenas. No entanto, esta alteração legal não invalidou a persistência de diversas práticas sociais relacionadas com aquele estatuto (Mondlane, 1996; Martins, 1974; Thomaz, 2001).

\section{Estudo 2: Representações e atitudes face à colonização}

29 Neste estudo os participantes em ambos os países foram confrontados com uma série de questões fechadas sobre as suas perceções face à colonização e as suas atitudes relativamente às relações pós-coloniais. As questões foram adaptadas da Escala de Representações e Atitudes face à Colonização desenvolvida por Licata e Klein (2007). A escala está estruturada em duas subescalas: a primeira sobre as representações do passado colonial e a segunda sobre as atitudes face à colonização e suas consequências. A escala foi testada previamente junto de estudantes portugueses e moçambicanos. No total foram inquiridos 284 estudantes, 180 moçambicanos e 104 portugueses.

\section{As representações do passado colonial}

Na primeira subescala os participantes eram convidados a associar o período colonial a um conjunto de dez fenómenos, indicando o seu nível de concordância face a essa associação através de uma escala de sete pontos, que ia do 1 ("Discordo totalmente") ao 7 ("Concordo totalmente"). $\mathrm{Na}$ apresentação das dez questões procurou-se que metade das mesmas representasse uma conotação negativa do período colonial, tal como foi destacada na historiografia moçambicana do pós-independência: "Exploração da mão de obra nas colónias pelos países colonizadores", "Exploração dos recursos dos países colonizados para benefício dos países colonizadores", "Atitude racista dos colonizadores europeus", "Destruição das culturas e modos de vida dos países colonizados" e "Luta dos colonizados para obtenção da independência". Na construção das outras cinco questões teve-se como referência a historiografia colonial: "Construção de vias de comunicação e de infraestruturas", "Evangelização dos países colonizados", "Criação de sistemas de educação e saúde nas colónias", "Pacificação dos países colonizados" e "Missão civilizacional dos europeus". Os resultados obtidos em Moçambique e em Portugal são apresentados na Tabela 2.

Tabela 2. Representações do processo de colonização 


\begin{tabular}{|l|c|c|}
\hline Questão & Moçambique & Portugal \\
\hline \begin{tabular}{l|c|}
\hline Luta dos colonizados para obtenção da \\
independência
\end{tabular} & 6,07 & 5,42 \\
\hline Exploração da mão de obra nas colónias pelos & $(1,89)$ & $(1,45)$ \\
\hline países colonizadores & 4,79 & 4,40 \\
\hline Exploração dos recursos dos países colonizados & $(2,64)$ & $(2,34)$ \\
\hline para benefício dos países colonizadores & 4,77 & 4,62 \\
\hline Construção de vias de comunicação e de & $(2,73)$ & $(2,16)$ \\
\hline infraestruturas económicas nas colónias & 4,64 & 4,79 \\
\hline Evangelização dos países colonizados & $(2,15)$ & $(1,65)$ \\
\hline Criação de sistemas de educação e saúde nas & 4,54 & 3,94 \\
\hline colónias & $(2,18)$ & $(1,79)$ \\
\hline Atitude racista dos colonizadores europeus & 4,45 & 4,99 \\
\hline Destruição das culturas e modos de vida dos países & $(2,27)$ & $(2,77)$ \\
\hline colonizados & 4,06 & 3,61 \\
\hline Pacificação dos países colonizados & $(2,64)$ & $(2,35)$ \\
\hline & 3,32 & 3,43 \\
\hline & $(2,74)$ & 4,27 \\
\hline & 3,66 & $(1,96)$ \\
\hline & $(2,31)$ & 4,14 \\
\hline & & $(1,72)$ \\
\hline
\end{tabular}

Questão: "Quando pensa na colonização, em que medida a associa aos seguintes aspetos?"

Escala: 1 = Discordo totalmente; 7 = Concordo totalmente

Os valores indicam a média de resposta e o desvio-padrão (entre parêntesis).

Da análise dos resultados deste conjunto de dez questões sobre o processo de colonização pode-se realizar um conjunto de três observações ${ }^{4}$. Em primeiro lugar é evidente uma divergência entre os participantes moçambicanos e os participantes portugueses no que respeita à avaliação do processo colonial. No caso dos moçambicanos verifica-se a predominância de uma perspetiva claramente negativa do período colonial, expressa numa elevada associação do mesmo à resistência africana à presença estrangeira ou à ação nociva dos europeus, ao nível da exploração da mão de obra africana e dos recursos económicos do país. No caso dos portugueses verificou-se um menor grau de concordância com os itens que apontam para os impactos negativos da colonização, nomeadamente no que concerne às questões relativas ao racismo e à exploração durante o período colonial.

Refira-se, em segundo lugar, que se registou uma considerável diversidade de posicionamentos, expressa num desvio-padrão frequentemente elevado, especialmente no caso dos participantes moçambicanos. Assim, os resultados obtidos nesta subescala, relativa às representações do processo colonial, estão longe de espelhar uma clara dicotomização das opiniões dos participantes em função do estatuto de "ex-colonizado" ou "ex-colonizador".

Para o entendimento destes resultados, é importante ter em conta que os conteúdos programáticos do ensino da história de Portugal tendem a enaltecer o período dos descobrimentos, predominando uma narrativa que destaca os aspetos positivos dos colonialismos, desagregados analiticamente das suas consequências negativas (Araújo \& Maeso, 2010, 2013; Mendes \& Valentim, 2012; Soares \& Jesuíno, 2004). 
34 Em contrapartida, os conteúdos programáticos do ensino da história em Moçambique, que enaltecem o papel de inúmeros moçambicanos na resistência multissecular a um invasor estrangeiro, poderão explicar a forte associação do período colonial à "Luta dos colonizados para obtenção da independência" (M=6,07). Adília Ribeiro (1997), a partir dos manuais oficiais do ensino da História de Moçambique para os 4., 5., 6. e 7. anos de escolaridade, oferece uma análise acerca dos fundamentos ideológicos subjacentes à versão oficial da história moçambicana, que poderá ter influenciado as representações do período colonial e da independência de Moçambique por parte da população mais jovem. Os reis e imperadores africanos, dinamizadores de movimentos (proto) nacionalistas urbanos ou da Frente de Libertação de Moçambique, constituem heróis moçambicanos frequentemente exaltados não só nos manuais escolares, mas também nos discursos políticos, na comunicação social ou na toponímia da cidade de Maputo.

Em terceiro lugar constata-se que o período colonial foi sobretudo associado à luta dos colonizados para obtenção da independência, tendo esta questão registado a média mais alta e a menor dispersão ao nível dos resultados, tanto na amostra moçambicana $(\mathrm{M}=6,07$; $\mathrm{DP}=1,89)$ como na amostra portuguesa $(\mathrm{M}=5,42 ; \mathrm{DP}=1,45)$. Esta representação dos participantes portugueses poderá dever-se ao carácter recente da "guerra colonial", com a qual os participantes poderão ter uma experiência vicariante de carácter mais emocional, em virtude da existência de familiares próximos que participaram no conflito em questão.

No que respeita aos participantes moçambicanos, predominou uma representação negativa do período colonial, associado à "Exploração da mão de obra nas colónias pelos países colonizadores" (M=4,79), à "Exploração dos recursos dos países colonizados para benefício dos países colonizadores" $(\mathrm{M}=4,77)$ e à "Atitude racista dos colonizadores europeus" $(\mathrm{M}=4,32)$.

No caso dos participantes portugueses, este conjunto de itens obteve uma média ligeiramente mais baixa, apontando para um menor nível de concordância face às afirmações que denunciam a exploração colonial: "Exploração da mão de obra nas colónias pelos países colonizadores" $(\mathrm{M}=4,40)$ e "Exploração dos recursos dos países colonizados para benefício dos países colonizadores" $(M=4,62)$. No caso do item que remete explicitamente para "Atitude racista dos colonizadores europeus", os participantes portugueses manifestaram alguma discordância $(M=3,61)$, enquanto os moçambicanos manifestaram maior concordância $(M=4,32)$. Apesar de as médias de resposta de ambos os grupos não se distanciarem muito do ponto neutro da escala, traduzem posicionamentos significativamente opostos. Verifica-se assim que, no caso dos participantes moçambicanos, a colonização traz à memória este conjunto de elementos negativos a muitos estudantes que nunca viveram o período colonial.

As desigualdades socioeconómicas entre portugueses e moçambicanos no período colonial constituíam uma realidade. De acordo com Penvenne (1993), no início da década de 1960 o salário anual médio de um trabalhador negro na indústria em Moçambique era, pelo menos, dez vezes inferior ao de um congénere branco, sendo que, por vezes, a diferença salarial não traduzia as respetivas competências. A situação agravava-se pelo facto de os negros estarem impedidos de se constituir em sindicatos e de reclamar direitos profissionais (Hedges, 1999). Com o salário que auferiam tornava-se problemático não só proporcionar melhores condições de educação para os próprios ou para os descendentes, como investir na melhoria das condições de habitação, em termos de acessibilidade ou de qualidade da construção (Martins, 1974). De acordo com Hedges (1999), 75\% dos 
investimentos destinavam-se à criação de infraestruturas de apoio à instalação dos colonos portugueses. As estradas, os caminhos de ferro, as estruturas hidroelétricas, o apetrechamento de portos, constituíam obras que confluíam para a criação ou melhoramento de centros de colonização.

Tendo em conta esta situação social, torna-se compreensível que os descendentes dessas populações africanas transportem memórias que salientem as desigualdades socioeconómicas e os processos de exploração da mão de obra africana. Em entrevistas semiestruturadas a cidadãos moçambicanos distribuídos pelas províncias de Maputo, Tete e Nampula, e por contextos urbanos e rurais, Mithá Ribeiro (1999) constatou a denúncia de desigualdades de tratamento (assentes em critérios raciais) em diversas situações do quotidiano colonial. Contudo, os entrevistados negaram a existência, em Moçambique, de um racismo nos moldes do apartheid. A este propósito Ribeiro (1999) utiliza os conceitos de "racismo paternalista" ou de "racismo de baixa intensidade", que seria um racismo mais subtil que o observado em outros contextos coloniais, mas com efeitos igualmente nefastos.

Como salientámos noutra ocasião, a existência de dois estatutos jurídicos distintos, que se traduziam em direitos de cidadania desiguais, bem como o facto de não terem sido disponibilizadas aos africanos as condições para que pudessem obter o estatuto de assimilado (rede escolar insuficiente, dificuldades económicas no acesso à educação, etc.) ilustram as desigualdades sociais existentes durante o período em análise. Ao mesmo tempo que se declarava que o projeto de assimilação dos indígenas constituía uma expansão civilizacional, criavam-se instrumentos legais e instituições que afirmavam continuamente a diferença e a desigualdade, entre os "nativos" por um lado, e os europeus, eurodescendentes e "assimilados" por outro, reforçando assim as fronteiras entre uns e outros. Face aos obstáculos existentes à liberdade e à participação no poder, a assimilação não terá constituído mais do que um mito. Como salienta Cunha (2001), o processo de assimilação não pretendia conferir ao negro, de uma forma gradual, o estatuto de maioridade política, mas antes incutir-lhe todo um conjunto de atitudes e de valores submissos e servis.

41 Durante o período colonial, o investimento público na educação foi escasso na metrópole, sendo ainda mais escasso nas colónias ${ }^{5}$. Em Moçambique, privilegiou sobretudo as regiões onde residiam as populações de ascendência europeia. 0 alastrar da resistência armada pelas províncias do Norte do país e a crescente industrialização impulsionaram a adoção de medidas políticas com vista ao aumento da qualificação de muitos moçambicanos. As críticas feitas ao sistema de ensino em Moçambique durante o período colonial são conhecidas (e.g. Newitt, 1995; Hedges, 1999). Por um lado, o Estado Novo não tinha como política prioritária a aposta na formação avançada dos recursos humanos. Sobretudo nas décadas de 1930 e 1940, o sistema educativo tinha como principal objetivo ensinar as crianças a "ler, escrever e contar", bem como veicular todo um conjunto de valores como a fé, o nacionalismo ou a família, expressos no famoso slogan "Deus, Pátria e Família". Por este motivo, o desenvolvimento do sistema de ensino em Moçambique foi lento e quase sempre suportado pelas ações da Igreja Católica, e no âmbito do ensino primário. Nos inícios da década de 1930 existia apenas uma escola secundária em Moçambique (na cidade de Lourenço Marques), com 208 alunos matriculados, a maioria dos quais de origem europeia. Por outro lado, as medidas educativas, tal como na metrópole, concentravam-se sobretudo nos grandes aglomerados urbanos - em detrimento das zonas rurais (Newitt, 1995) -, precisamente nas áreas onde a população de origem europeia 
estava mais concentrada, e de forma a enquadrar os filhos da crescente população branca (Hedges, 1999). Critica-se frequentemente o etnocentrismo (os alunos eram obrigados a conhecer em pormenor a geografia de Portugal continental, negligenciando-se o estudo de Moçambique), a ênfase conferida ao ensino da religião católica ou do nacionalismo português (Thomaz, 2001; Ngomane, 2012), a insuficiência e a má preparação dos professores (Hedges, 1999), bem como a sub-representação de estudantes africanos - em 1960, quando o ensino era controlado pelo Estado, os alunos negros representavam apenas $13 \%$ do total de matrículas, percentagem muito menor que a de 1930, quando estes alunos constituíam mais de 50\% dos inscritos (Hedges, 1999).

No final do período colonial, sobretudo a partir do início da guerra de libertação, registou-se uma maior preocupação ao nível da escolarização das populações africanas. No campo da educação desenvolveu-se uma rede de estabelecimentos de ensino secundário, por intermédio do Estado e da Igreja, nos principais centros urbanos e em especial no Sul do país.

Nascidos na fase final da guerra dos dezasseis anos ${ }^{6}$ e portanto beneficiários de um período de crescimento socioeconómico, os jovens moçambicanos que participaram neste estudo consideraram que a independência permitiu o alargamento de um conjunto de direitos sociais de cidadania a muitos moçambicanos, relacionados particularmente com o direito à educação. A partir da década de 1990 e sobretudo no novo milénio, multiplicaram-se na cidade de Maputo diversos estabelecimentos de ensino privado, tanto ao nível do ensino secundário como do superior. É neste contexto de alargamento das oportunidades de acesso à educação e aumento das expectativas sociais que importa compreender a associação da sociedade colonial à exploração, discriminação social e consequente desigualdade de oportunidades.

No que diz respeito ao desenvolvimento socioeconómico e à construção de infraestruturas durante o período colonial, os resultados dos participantes moçambicanos e portugueses aproximam-se. No caso dos moçambicanos a associação do colonialismo à "Construção de vias de comunicação e de infraestruturas económicas nas colónias" (M=4,64) ou à "Criação de sistemas de educação e saúde nas colónias" $(M=4,45)$ foi, no geral, pouco distante do ponto neutro da escala. Assim, no que respeita a este conjunto de itens, relacionados com a construção de infraestruturas e desenvolvimento, os resultados dos participantes moçambicanos aproximam-se dos resultados dos participantes portugueses: "Construção de vias de comunicação e de infraestruturas económicas nas colónias" $(\mathrm{M}=4,79)$ ou à "Criação de sistemas de educação e saúde nas colónias" $(M=4,99)$. No caso dos moçambicanos, a dispersão dos resultados foi maior, demonstrando estes maior ambivalência face a estas questões do que os participantes portugueses.

Tal ambivalência pode advir das "contradições" entre os discursos apreendidos nos bancos da escola e os testemunhos de familiares, como foi referido nos grupos focais realizados em Maputo (ver Feijó \& Cabecinhas, 2009). Na reprodução das conversas mantidas no seio da família, nomeadamente com tios e avós, alguns estudantes transmitiram uma imagem mais positiva das condições de vida durante o período colonial. A reprodução destes discursos positivos relativamente ao passado colonial foi, normalmente, realizada por comparação aos problemas sentidos no presente no sector da educação.

Ainda que o território moçambicano fosse marcado por fortes assimetrias regionais (Newitt, 1995; Isaacman \& Isaacman, 1983), com graves carências ao nível de infraestruturas de educação e saúde que beneficiavam sobretudo a população branca e 
urbana, na literatura científica é possível encontrar diversas referências ao desenvolvimento registado em Moçambique no período colonial.

As análises reportam às infraestruturas agrícolas e industriais, de transporte e de comunicação a partir da década de 1940 (Newitt, 1995; Martins, 1998; Penvenne, 1993).

A valorização de aspetos relacionados com o desenvolvimento económico e social do Moçambique colonial pode ser compreendida como uma crítica ao presente. Trata-se de discursos emitidos por uma jovem elite africana, ciente do facto de grande parte das infraestruturas existentes em Maputo ter sido herdada do período colonial, que olha com algumas reservas a capacidade produtiva do país após a independência. Contudo, os participantes moçambicanos manifestaram pouca concordância relativamente a um conjunto de ideias eurocêntricas, muito em voga tanto na historiografia como nos discursos políticos do Estado Novo, relacionadas com a "Missão civilizacional dos europeus" $(M=3,66)$ e com a "Pacificação dos países colonizados" (M=3,74). Para diversos estudantes moçambicanos, as populações africanas experimentavam um processo de desenvolvimento civilizacional que foi interrompido pela chegada dos colonos europeus, que vieram impor um novo modelo sociocultural, fazendo tábua rasa das culturas e tradições locais. Já no caso dos participantes portugueses, as respostas a estas questões situaram-se muito próximas do ponto neutro da escala: "Missão civilizacional dos europeus" $(M=4,14)$, com a "Pacificação dos países colonizados" $(M=4,27)$. Mais uma vez, o nível de dispersão das respostas face a estas questões é menor no caso dos participantes portugueses do que no caso dos participantes moçambicanos, apontando para uma maior ambivalência nas respostas destes últimos.

\section{Atitudes face à colonização e relações pós- coloniais}

49 A segunda subescala permitiu estudar as atitudes dos participantes face à colonização e também a sua opinião sobre as suas consequências, nomeadamente ao nível das relações pós-coloniais.

O primeiro item desta subescala visa medir a atitude geral em relação à colonização, enquanto o segundo e o terceiro medem a relativização da colonização. Em relação ao primeiro item - "A colonização, seja qual for a circunstância, é sempre uma coisa má" -, a média de resposta dos participantes moçambicanos $(M=4,81)$ indica que de um modo geral concordam com a afirmação. No entanto, verifica-se grande divergência de opinião no seio destes mesmos participantes, como se pode constatar pelo elevado valor do desviopadrão (DP=2,38). Em contrapartida, em média, os portugueses discordaram da afirmação e o nível de divergência de opinião é menor ( $\mathrm{M}=3,41$; $\mathrm{DP}=1,55)$.

51 Em relação ao segundo item - "Em algumas circunstâncias, a colonização pode ser uma coisa boa" -, mais uma vez se observa uma grande divergência de opiniões dentro do grupo dos moçambicanos, o que se traduz numa média que não difere do ponto neutro $(\mathrm{M}=4,09 ; \mathrm{DP}=2,27)$. Por seu turno, os portugueses tenderam a concordar com a afirmação $(\mathrm{M}=4,88 ; \mathrm{DP}=1,47)$. Quanto ao terceiro item - "Não podemos julgar os colonizadores com base nos valores de hoje" -, verifica-se, mais uma vez, uma maior divergência de opiniões no seio dos moçambicanos $(M=4,48 ; S D=2,21)$ do que no seio dos portugueses $(M=5,02$; $\mathrm{SD}=1,52$ ), sendo o grau de concordância destes últimos superior. Os dados destes três itens em conjunto apontam para uma grande variabilidade de opiniões por parte dos 
participantes moçambicanos, indicando que o assunto não é consensual. Os participantes portugueses tendem a relativizar a colonização: de um modo geral manifestam o seu desacordo face à afirmação de que a colonização é "sempre uma coisa má" e concordam claramente que "Não podemos julgar os colonizadores com base nos valores de hoje". Este padrão de resposta é claramente defensivo, de modo a proteger a autoestima nacional.

Tabela 3. Atitudes face à colonização e relações pós-coloniais

\begin{tabular}{|c|c|c|}
\hline $\begin{array}{l}\text { Até que ponto concorda com as seguintes } \\
\text { afirmações? }\end{array}$ & Moçambique & Portugal \\
\hline $\begin{array}{l}\text { A colonização, seja qual for a circunstância, é } \\
\text { sempre uma coisa má. }\end{array}$ & $\begin{array}{c}4,81 \\
(2,38)\end{array}$ & $\begin{array}{c}3,41 \\
(1,55)\end{array}$ \\
\hline $\begin{array}{l}\text { Em algumas circunstâncias, a colonização pode ser } \\
\text { uma coisa boa. }\end{array}$ & $\begin{array}{r}4,09 \\
(2,27)\end{array}$ & $\begin{array}{c}4,88 \\
(1,47)\end{array}$ \\
\hline $\begin{array}{l}\text { Não podemos julgar os colonizadores com base } \\
\text { nos valores de hoje. }\end{array}$ & $\begin{array}{c}4,48 \\
(2,21)\end{array}$ & $\begin{array}{c}5,02 \\
(1,52)\end{array}$ \\
\hline $\begin{array}{l}\text { Os países colonizadores ainda hoje beneficiam das } \\
\text { suas ações coloniais. }\end{array}$ & $\begin{array}{c}4,93 \\
(2,20)\end{array}$ & $\begin{array}{c}4,35 \\
(1,32)\end{array}$ \\
\hline $\begin{array}{l}\text { Em geral, os países colonizadores tiveram boas } \\
\text { ações para com os colonizados. }\end{array}$ & $\begin{array}{l}2,76 \\
(2,03)\end{array}$ & $\begin{array}{c}3,19 \\
(1,29)\end{array}$ \\
\hline $\begin{array}{l}\text { A situação das ex-colónias era melhor durante o } \\
\text { período colonial do que é agora. }\end{array}$ & $\begin{array}{l}2,58 \\
(2,04)\end{array}$ & $\begin{array}{c}4,00 \\
(1,39)\end{array}$ \\
\hline $\begin{array}{l}\text { Os Governos europeus deviam pedir desculpas } \\
\text { publicamente pela colonização. }\end{array}$ & $\begin{array}{c}5,06 \\
(2,26)\end{array}$ & $\begin{array}{c}3,49 \\
(1,74)\end{array}$ \\
\hline $\begin{array}{l}\text { Os Governos europeus deviam oferecer } \\
\text { compensações às suas antigas colónias. }\end{array}$ & $\begin{array}{r}5,29 \\
(2,08)\end{array}$ & $\begin{array}{c}3,86 \\
(1,70)\end{array}$ \\
\hline $\begin{array}{l}\text { A colonização criou laços de amizade entre os } \\
\text { países europeus e as suas ex-colónias. }\end{array}$ & $\begin{array}{l}4,88 \\
(2,08)\end{array}$ & $\begin{array}{l}4,38 \\
(1,27)\end{array}$ \\
\hline
\end{tabular}

Questão: Até que ponto concorda com as seguintes afı rmações?

Escala: 1 = Discordo totalmente; 7 = Concordo totalmente.

Os valores indicam a média de resposta e o desvio-padrão (entre parêntesis)

52 Nos dois itens seguintes, as respostas dos participantes moçambicanos e portugueses vão na mesma direção. Ambos os grupos concordam que "Os países colonizadores ainda hoje beneficiam das suas ações coloniais", embora o nível de concordância com esta afirmação seja maior entre os participantes moçambicanos $(M=4,93)$ do que entre os participantes portugueses $(\mathrm{M}=4,35)$.

53 Ambos os grupos manifestaram o seu claro desacordo com a afirmação "Em geral, os países colonizadores tiveram boas ações para com os colonizados", embora o nível de discordância com esta afirmação seja maior entre os moçambicanos $(M=2,76)$ do que entre os portugueses $(\mathrm{M}=3,19)$.

$\mathrm{O}$ item relativamente ao qual os participantes moçambicanos manifestam maior grau de discordância é o seguinte: "A situação das ex-colónias era melhor durante o período colonial do que é agora" $(\mathrm{M}=2,58)$. Em contrapartida, a resposta dos participantes portugueses coincide com o ponto neutro da escala $(M=4,00)$, denotando que, em média, nem concordam nem discordam da afirmação.

Relativamente a compensações morais ou financeiras, as opiniões dos participantes moçambicanos e portugueses diferem claramente. Os moçambicanos consideram que os 
governos europeus deviam pedir desculpas publicamente pela colonização $(M=5,06)$ e deviam oferecer compensações financeiras às suas ex-colónias $(M=5,29)$. Já os portugueses tendem a discordar de ambas as medidas, especialmente da primeira $(M=3,49)$.

Por último, os moçambicanos concordam que "A colonização criou laços de amizade entre os países europeus e as suas ex-colónias" (embora se verifique alguma divergência de opiniões no seio do grupo, a média é positiva: $\mathrm{M}=4,88$; $\mathrm{DP}=2,08$ ). Já os portugueses parecem estar mais reticentes, uma vez que a resposta a este item se aproxima do ponto neutro da escala $(\mathrm{M}=4,38 ; \mathrm{DP}=1,27)$.

No questionário foram também colocadas questões sobre os níveis de identificação dos participantes com diversos grupos. Dado o carácter comparativo desta pesquisa, foram medidos os níveis de identificação não só com os grupos de pertença dos participantes, mas também com outros grupos de comparação considerados relevantes no âmbito deste estudo (ver Cabecinhas \& Feijó, 2010).

Os níveis de identificação foram medidos através de escalas fechadas de sete pontos: para cada grupo o inquirido deveria indicar em que medida se sentia identificado ou não (1=Nada identificado; 7=Muito identificado). Em cada país foram medidos os níveis de identificação nacional (moçambicanos, portugueses), supranacional (africanos, europeus) e linguística (língua portuguesa e outras línguas faladas em Moçambique).

Ambos os grupos manifestaram níveis de identificação nacional mais elevados do que os níveis de identificação supranacional. Os moçambicanos declararam um nível de identificação nacional ligeiramente mais elevado do que os portugueses, sendo essa diferença mais acentuada ao nível da identificação supranacional (ao seja, os moçambicanos identificam-se mais com os "africanos" do que os portugueses com os "europeus"). o mesmo padrão repetiu-se em relação aos níveis de identificação linguística. Embora os participantes portugueses se tenham declarado muito identificados com a "língua portuguesa", os moçambicanos declararam níveis de identificação mais elevados com a sua língua materna, especialmente aqueles cuja língua materna não é o português. Estes dados são concordantes com estudos anteriores (e.g., Cabecinhas, 2007) que apontam para o facto de os membros de grupos minoritários, ou que durante muito tempo o foram, tenderem a ter níveis de identificação endogrupal superiores aos dos membros dos grupos tradicionalmente dominantes.

Os moçambicanos declaram um nível de identificação com os portugueses superior ao nível de identificação destes com os primeiros, o que poderá dever-se ao facto de a amostra moçambicana ser constituída por jovens com forte contacto com as culturas europeias (em termos familiares, profissionais e educacionais). Pelo contrário, a amostra portuguesa é constituída por jovens com pouco contacto direto com as culturas africanas, como podemos aferir através das questões sobre as redes de socialidades e as eventuais vivências ou viagens ao estrangeiro. No entanto, tal poderá também ser explicado à luz do processo de colonização, baseado numa relação profundamente assimétrica entre colonizador e colonizados, que pressupunha uma maior ligação dos colonizados ao país colonizador do que o contrário7.

61 Confrontando os dados dos níveis de identificação com os relativos às representações e atitudes face à colonização, verificamos que, apesar de a colonização ser encarada de forma mais negativa pelos participantes moçambicanos do que pelos participantes portugueses, os moçambicanos tendem a concordar que "A colonização criou laços de 
amizade entre os países europeus e as suas ex-colónias", aspeto relativamente ao qual os portugueses manifestam menor grau de concordância.

\section{Considerações finais}

Da análise dos dados recolhidos em Moçambique e em Portugal podemos verificar que as representações do processo colonial e as atitudes face à colonização apresentam divergências consideráveis, mas também algumas convergências. As divergências são especialmente visíveis no que respeita à avaliação do processo de colonização. No entanto, essas divergências não se traduzem numa simples oposição entre as perspetivas de cidadãos da ex-potência colonial e os cidadãos das ex-colónias. Em ambos os grupos podemos observar algumas ambivalências e contradições no que concerne às questões coloniais e pós-coloniais.

No que respeita às representações da história nacional, verificaram-se consideráveis divergências relativamente às memórias históricas evocadas referentes ao período colonial. Enquanto os participantes portugueses focaram sobretudo os "descobrimentos", os congéneres moçambicanos destacaram a conquista de independência e a luta pela libertação do jugo colonial. Os efeitos nefastos da colonização foram evocados pelos moçambicanos, mas silenciados pelos portugueses; isto é, enquanto uns se focaram no "encontro" os outros focaram-se no "desencontro".

Como referimos em outra ocasião, "a boa gestão das memórias coletivas constitui um elemento crucial para o sucesso dos processos de reconciliação e para a possibilidade de um verdadeiro diálogo entre grupos" (Cabecinhas \& Nhaga, 2008: 109). Neste caso, uma boa gestão das memórias da colonização pressupõe uma atenção em pé de igualdade para ambas as perspetivas face a esta complexa questão.

Os resultados obtidos demonstram que as memórias "comuns" da história da colonização portuguesa assumem significados diferenciados entre os grupos envolvidos. É fundamental trabalhar estas memórias para uma boa gestão das relações pós-coloniais entre os diversos povos que falam a língua portuguesa.

Embora não tenhamos explorado neste artigo o papel das diversas fontes de informação histórica, em trabalhos anteriores pudemos constatar que os manuais escolares, os média e as conversas com familiares assumem um papel preponderante. $O$ ensino da história constitui, em qualquer país, um processo bastante politizado. Contrariamente à historiografia portuguesa - que confere amplo destaque às navegações marítimas, secundarizando aspetos como a escravatura ou o trabalho forçado, bem como o carácter discriminatório da exploração colonial -, no ensino da história de Moçambique são empolados aspetos como a exploração dos recursos humanos e naturais em proveito dos povos colonizadores e em prejuízo dos colonizados (Ribeiro, 1997). Se a historiografia portuguesa não deixa de ter a função de fortalecimento do orgulho e autoestima nacional, na congénere moçambicana o enfoque num passado comum marcado pela exploração $\mathrm{e}$ pela discriminação racial exerce da mesma forma uma função política. Um jovem Estado como Moçambique, marcado pela heterogeneidade sociocultural (linguística, religiosa ou de sistemas de parentesco), atravessado por um conflito armado de dezasseis anos que não deixou de assumir uma dimensão de guerra civil (Geffray, 1990) e marcado por profundas desigualdades sociais e regionais, continua a enfrentar o desafio de edificação da unidade nacional. Não deixa de ser neste contexto de "moçambicanização" (Macamo, 
1998: 38-60) - portanto, de (re)criação e promoção de uma identidade nacional ${ }^{8}$ - que as populações são hoje expostas a um discurso político que enfatiza uma condição histórica de exploração comum, bem como as ações heroicas dos grupos dirigentes na libertação do país (Cahen, 1994; Feijó, 2010). O processo de reinvenção da moçambicanidade não deixa de ter como função a legitimação das elites nacionais9. A perceção de um percurso histórico idêntico, pautado por uma situação de desvantagem económica e social, relativamente a uma comunidade estrangeira, privilegiada e opressora encontra-se na génese de um discurso nacionalista de essência anticolonial.

Se, de uma forma geral, por parte dos participantes moçambicanos se destacou um forte nível de concordância relativamente ao carácter opressor, discriminatório e racista do sistema colonial, não deixou de se registar uma forte diversidade de posicionamentos relativamente a esses mesmos aspetos.

Trata-se de um grupo socialmente heterogéneo, não só em termos de origens nacionais (com forte presença de indo-moçambicanos e luso-moçambicanos), como de capitais de origem ou trajetórias sociais (Feijó e Cabecinhas, 2009) e portanto com representações distintas sobre o período colonial e a independência de Moçambique.

Contrariamente aos congéneres moçambicanos, os participantes portugueses não foram tão ativos na associação do período colonial à exploração dos recursos locais para proveito da metrópole ou à discriminação com base em critérios raciais. Trata-se de aspetos que não são destacados com o mesmo enfoque no ensino oficial da história de Portugal que, ao invés, enfatiza a epopeia e a heroicidade dos navegadores portugueses do século XV. Por outro lado, os resultados espelham a persistência de representações lusotropicalistas da sociedade colonial, reforçadas em muitos casos pela existência de ligações familiares com populações residentes nas ex-colónias portuguesas, expostas na época a uma propaganda colonial que enfatizava a vocação colonial portuguesa (Castelo, 1998; Thomaz, 2002). A partir da década de 1960, a revogação de todo um conjunto de legislação discriminatória, o alargamento de oportunidades de ensino a populações locais (particularmente nas escolas técnico-profissionais), a coexistência social de populações de diferentes origens étnicas em moldes diferentes daqueles praticados na África do Sul e, inclusivamente, a existência de inúmeras populações mistas permitem compreender a ideia de "colonialismo doce", ainda que num quadro de "racismo de proximidade" (Cahen, entrevistado por Macedo \& Maloa, 2013: 157). A traumática saída dos países africanos e a existência na sociedade portuguesa de gerações vivas com passado colonial problematizaram, sobretudo nas primeiras décadas, uma reflexão crítica sobre as relações luso-moçambicanas em contexto colonial.

70 Comparativamente com os participantes portugueses, os congéneres moçambicanos demonstram-se mais céticos relativamente a discursos eurocêntricos relacionados com a missão civilizacional dos portugueses no período colonial, bem como com a respetiva ação pacificadora. Pelo contrário predominou uma opinião generalizada de que deveriam ser credores de compensações financeiras e de um formal pedido de desculpa.

71 Globalmente, os dados espelham algumas representações hegemónicas sobre a história, que se traduzem em imagens do passado que legitimam a ordem social presente, mas também evidenciam expressões da memória social como um "campo de disputa" entre grupos. As memórias sobre o "passado comum" são vivenciadas com diferentes tonalidades emocionais e apresentam significados diferenciados para moçambicanos e portugueses. Como refere Mia Couto, "Falar de guerras é um assunto nada pacífico. Falar de memórias é um assunto cheio de esquecimento" (2009: 200). 


\section{BIBLIOGRAPHY}

ANDERSON, Benedict (1991), Imagined Communities: Reflections on the origins and spread of nationalism. Londres: Verso.

ARAÚJO, Marta \& MAESO, Silvia Rodríguez (2013), “A presença ausente do racial: discursos políticos e pedagógicos sobre História, 'Portugal' e (pós-)colonialismo”. Educar em Revista, 47: 145-171.

ARAÚJO, Marta \& MAESO, Silvia Rodríguez (2010), “Explorando o eurocentrismo nos manuais portugueses de História”. Estudos de Sociologia, 15(28): 239-270.

CABECINHAS, Rosa (2007), Preto e Branco. A Naturalização da discriminação racial. Porto: Campo das Letras.

CABECINHAS, Rosa (2011), "Narrativas identitárias e memória social: estudos comparativos em contexto lusófono", in J. Gama et al. (coord.) Cultura Portuguesa, Interculturalidade e Lusofonia. Braga: Universidade Católica Portuguesa, 171-184.

CABECINHAS, Rosa \& NHAGA, Nesilita (2008), “Memórias coloniais e diálogos pós-coloniais: Guiné-Bissau e Portugal”, in R. Cabecinhas \& L. Cunha (eds.) Comunicação Intercultural: Perspectivas, dilemas e desafios: 109-132. Porto: Campo das Letras.

CABECINHAS, Rosa \& FEIJÓ, João (2010), “Collective memories of Portuguese colonial action in Africa: Representations of the colonial past among Mozambicans and Portuguese youths". International Journal of Conflict and Violence, 4(1): 28-44.

CAHEN, Michel (1994), “Mozambique, Histoire géopolitique d'un pays sans nation”. Lusotopie, 1-2: 213-266.

CARVALHO, Michelly \& CABECINHAS, Rosa (2013), "The Orthographic (dis)Agreement and the Portuguese identity threat". Portuguese Literary \& Cultural Studies, 25: 82-95.

CASTELO, Cláudia (1998), «O modo português de estar no Mundo», o luso-tropicalismo e a ideologia colonial portuguesa (1933-1961). Porto: Edições Afrontamento.

CASTELO, Cláudia (2007), Passagens para África. O povoamento de Angola e Moçambique com Naturais da Metrópole (1920-1974). Porto: Edições Afrontamento.

CATROGA, Fernando (1996), "Ritualizações da História”, in Luís Torgal, José Mendes \& Fernando Catroga, História da História em Portugal - Sécs. XIX-XX, Lisboa: Círculo de Leitores, 547-671.

COUTO, Mia (2009), E se Obama fosse africano? E outras interinvenções. Lisboa: Caminho.

CUNHA, Luís (2001), A Nação nas Malhas da sua Identidade - O Estado Novo e a construção da identidade nacional. Porto: Edições Afrontamento.

CUNHA, Luís (2006), Memória Social em Campo Maior: Usos e percursos da fronteira. Lisboa: Edições Dom Quixote.

FEIJÓ, João (2010), Do Passado Colonial à Independência - Discursos do semanário Savana nas celebrações da independência de Moçambique. Maputo: Alcance Editores.

FEIJÓ, João \& CABECINHAS, Rosa (2009), "Representações da História de Moçambique por parte de estudantes universitários de Maputo”. Anuário Internacional de Comunicação Lusófona, 7: 37-52. 
FREYRE, Gilberto (1933), Casa Grande e Senzala. Lisboa: Livros do Brasil.

GEFFRAY, Christian (1990), La Cause des armes au Mozambique. Anthropologie d'une guerre civile. Paris: Karthala.

HEDGES, David (coord.) (1993), História de Moçambique, Volume 2: Moçambique no auge do colonialismo, 1930-1961. Maputo: Livraria Universitária, Universidade Eduardo Mondlane.

ISAACMAN, Allen \& ISAACMAN, Barbara (1983), Mozambique: From Colonialism to Revolution, 1900-1982, Boulder Colorado: Westview Press.

LICATA, Laurent \& KLEIN, Olivier (2007), A Scale of Representations and Attitudes towards Colonization. Manuscrito não publicado, Bruxelas.

LICATA, Laurent; KLEIN, Olivier \& GÉLY, Raphael (2007), "Mémoire des conflits, conflits de mémoires: une approche psychosociale et philosophique du rôle de la mémoire collective dans les processus de réconciliation intergroupe”. Social Science Information, 46(4): 563-589.

LIU, James \& HILTON, Denis (2005), "How the past weighs on the present: Towards a social psychology of histories”. British Journal of Social Psychology, 44: 537-556.

LOURENÇO, Eduardo (2001), O Labirinto da Saudade. Lisboa: Gradiva.

MACAMO, Elísio (1996), “A nação moçambicana como comunidade de destino”. Lusotopie, 4, 355-364.

MACAMO, Elísio (1998), “A influência da religião na formação das identidades sociais no sul de Moçambique”, in Carlos Serra (dir.), Identidade, Moçambicanidade, Moçambicanização. Maputo: Livraria Universitária, Universidade Eduardo Mondlane.

MACEDO, Lurdes; MARTINS, Moisés de Lemos \& CABECINHAS, Rosa (2011), “Blogando a lusofonia: experiências em três países de língua oficial portuguesa". Anuário Internacional de Comunicação Lusófona, 9: 121-140.

MACEDO, Victor Miguel Castillo \& MALOA, Joaquim (2013), “Em Moçambique só há partidos de direita". Plural, 20(1): 155-174.

MARGARIDO, Alfredo (2000), A Lusofonia e os Lusófonos: Novos mitos portugueses. Lisboa: Edições Universitárias Lusófonas.

MARTINS, Elísio (1974), Colonialism and Imperialism in Mozambique - The beginning of the end. Denmark: Akademisk Forlag, Softcover.

MARTINS, José Abílio Lomba (1998), “Sistemas de colonização e conceitos de desenvolvimento. I parte: do pacto colonial às independências". Africana, 19: 21-69.

MARTINS, Moisés de Lemos (2006), "A Lusofonia como promessa e o seu equívoco lusocêntrico", in M. L. Martins, H. Sousa \& R. Cabecinhas (eds.). Comunicação e Lusofonia - Para uma abordagem crítica da cultura e dos media. Porto: Campo das Letras: 79-87.

MENDES, Vanessa \& VALENTIN, Joaquim (2012), "O luso-tropicalismo nos manuais de História e de Português do ensino primário português no período colonial: um estudo exploratório". Psicologia e Saber Social, 1 (2): 221-231.

MIRANDA, Joana (2002), A Identidade Nacional. Do mito ao sentido estratégico. Oeiras: Celta.

MOLLER, Renato Cesar; SÁ, Celso Pereira \& BEZERRA, Fernando C. C. (2004), “Representações sociais vivas do descobrimento do Brasil: a memória social atualizada de brasileiros e portugueses". Psicologia, XVII(2), 405-417. 
MONDLANE, Eduardo (1996), Lutar por Moçambique. Maputo: Centro de Estudos Africanos, Universidade Eduardo Mondlane.

NEWITT, Malyn (1995), História de Moçambique. Mem Martins: Publicações Europa-América. NGOMANE, Nataniel (2012), “Quem quer ser apagado?”. Semanário Sol, 06/01/2012.

PENVENNE, Jeanne (1993), Trabalhadores de Lourenço Marques (1870-1974), Colecção Estudos, n.o 9. Maputo: Arquivo Histórico de Moçambique.

REITER, Bernd (2005), “Portugal: national pride and imperial neurosis”. Race Class, 47, 79-91. RIBEIRO, Gabriel Mithá (1999), As Representações Sociais dos Moçambicanos: Do passado colonial à democratização. Esboço de uma cultura política. Dissertação de Mestrado em Desenvolvimento Económico e Social em África, Centro de Estudos Africanos, Instituto Superior de Ciências do Trabalho e da Empresa.

RIBEIRO, Maria Adília Gomes (1997), Educação / História / Ideologia em Moçambique - Uma análise do conteúdo dos manuais escolares de História do 1.ํ e 2. grau do ensino primário. Dissertação de Mestrado em Estudos Africanos, Universidade Técnica de Lisboa, Instituto Superior de Ciências Sociais e Políticas.

SOARES, Célia \& JESUÍNO, Jorge Correia (2004), "Memória social e representações sobre o descobrimento do Brasil: análise dos manuais portugueses de história”. Psicologia, 17(2), 321-337. SOBRAL, José Manuel (2010), “Dimensões étnicas e cívicas e glorifi cação do passado em representações da identidade portuguesa numa perspectiva comparada", in J. M. Sobral \& J. Vala (eds.) (2010), Identidade Nacional, Inclusão e Exclusão Social. Lisboa: Imprensa de Ciências Sociais.

THOMAZ, Omar Ribeiro (2002), Ecos do Atlântico Sul. Rio de Janeiro: Editora da UFRJ.

THOMAZ, Omar Ribeiro (2001), “Contextos cosmopolitas: missões católicas, burocracia colonial e a formação de Moçambique (notas de uma pesquisa em curso)”. Estudos Moçambicanos, 19: 27-59.

UÍNGE, Destina (dir.) (2008), Anuário Estatístico 2007. Maputo: Instituto Nacional de Estatística.

VALA, Jorge \& SAINT-MAURICE, Ana (2004), "Representações sociais sobre o descobrimento do Brasil: os actores e a colonização". Psicologia, XVII(2), 385-404.

VALA, Jorge (2013), "Racisms: Social representations, racial prejudice and normative pressures". Papers on Social Representations, 22, 6.1-6.29.

VALENTIN, Joaquim (2011) "Representações sociais do luso-tropicalismo e olhares cruzados entre portugueses e africanos”, in M. J. Simões (coord.), Imagotipos Literários: Processos de (des)configuração na imagologia literária. Coimbra: Centro de Literatura Portuguesa, 55-75.

WERTCH, James V. (2002), Voices of Collective Remembering. Cambridge: Cambridge University Press.

\section{NOTES}

1. A palavra "lusofonia" vem assumindo múltiplos signifi cados, não cabendo no âmbito deste artigo discutir a complexidade deste conceito. Em Moçambique o conceito de lusofonia tem sido bastante questionado, como demonstram análises realizadas sobre os discursos identitários produzidos na blogosfera moçambicana (Macedo et al., 2011). Para compreender as representações da lusofonia em Moçambique, importa ter em conta que, em 1975, a taxa de analfabetismo no país (portanto de não falantes de português) era de 95\% (Isaacman \& Isaacman, 
1983) e que, trinta anos após a independência, rondava os 50\% (Uínge, 2008). Curiosamente, como explica Malyn Newitt (1995: 470), nos primeiros anos da independência de Moçambique, "desenvolveram-se esforços ainda maiores para aumentar os conhecimentos da língua e alfabetizar as pessoas na língua de Camões e Caetano do que os alguma vez desenvolvidos pelos próprios Portugueses".

2. Refira-se que a palavra "descobrimentos" encerra em si um claro enviesamento etnocêntrico. Se foram descobridores, os portugueses não deixaram de ser descobertos, pelo que este processo não deve negligenciar os múltiplos olhares e representações decorrentes desses encontros.

3. A este propósito, recordamos as palavras de Mia Couto (2009: 191-192): "Não foi Portugal que descolonizou os países africanos. A descolonização só pode ser feita pelos próprios colonizados. E nós todos éramos colonizados. Descolonizámo-nos uns aos outros, uns e outros."

4. Os dados referentes a Moçambique no que respeita a esta subescala foram previamente apresentados em Feijó e Cabecinhas (2009). Nesse artigo procede-se a uma discussão dos mesmos em comparação com os resultados obtidos em Portugal.

5. De acordo com os Censos de 1970, a taxa de analfabetismo em Portugal era de $21 \%$, enquanto em Moçambique rondava os $95 \%$ (Isaacman \& Isaacman, 1983).

6. A designação do conflito armado que envolveu as forças governamentais e as da Renamo entre o período pós-independência de Moçambique e a assinatura dos Acordos de Paz de 1992 está envolta em polémica. A Renamo prefere a designação "guerra civil" (motivada pelo despotismo governamental), enquanto a Frelimo insiste na designação "guerra de destabilização" (protagonizada pelo governo de Ian Smith e pelas forças do apartheid). "Guerra dos dezasseis anos" constitui uma designação mais neutra.

7. Tal é bem visível nos manuais escolares durante o período colonial. Como foi referido anteriormente, os estudantes no "Ultramar" deveriam aprender a geografi a e a história de Portugal, mas não era exigido aos estudantes na metrópole o conhecimento, em igual nível de profundidade, da geografia das colónias, sendo a história e as tradições culturais completamente descuradas.

8. De acordo com Macamo (1998), a existência de um discurso acerca do nacionalismo moçambicano, bem como a difusão de debates acerca da sua essência conduzem à (re)criação da moçambicanidade. $O$ processo de moçambicanização estará dependente da integração das diversas regiões, em termos de vias de transporte e de comunicação, e da capacidade de o Estado proporcionar a todas as populações o acesso ao sistema educativo e à segurança social.

9. Qualquer forma de nacionalismo constitui um processo idealizado pelas elites que, em parte, sustentam a sua própria existência. As nações representam por isso "comunidades imaginadas" (Anderson, 1991), traduzindo não tanto uma essência, mas um processo dinâmico, em permanente (re)construção e (re) invenção, de acordo com os interesses dos grupos sociais dominantes.

医. Artigo desenvolvido no âmbito do projeto "Narrativas identitárias e memória social: a (re)construção da lusofonia" (PTDC/CCI-COM/105100/2008), financiado por Fundos FEDER através do Programa Operacional Fatores de Competitividade - COMPETE e por Fundos Nacionais através da FCT - Fundação para a Ciência e a Tecnologia. 


\section{ABSTRACTS}

As representações sociais da história veiculadas pelos média e disseminadas nas enciclopédias ditas globais são talvez um dos mais evidentes exemplos do quanto ainda há a fazer para descolonizar o conhecimento. Nessas narrativas o "Norte" tende a ser representado como o motor da história, enquanto o "Sul" é remetido ao esquecimento. Neste artigo discutimos os resultados de estudos realizados junto de jovens em Moçambique e em Portugal. São analisadas as representações de jovens sobre a história nacional (Estudo 1) e sobre o processo de colonização e as suas consequências (Estudo 2). As convergências e as divergências entre os resultados obtidos em ambos os países são discutidas tendo em conta o papel das identidades sociais na estruturação das memórias coletivas.

Social representations of history conveyed by the media and disseminated in "global" encyclopedias are perhaps among the clearest examples of how much remains to be done to decolonize knowledge. In these narratives the "North" tends to be represented as the engine of history while the "South" is consigned to oblivion.

This paper discusses the results of studies conducted among young people in Mozambique and Portugal. Their representations on national history (study 1 ) and the process of colonization and its consequences (study 2) are analyzed. Convergences and divergences between the results obtained in both countries are discussed taking into account the role of social identities in structuring collective memories.

Les représentations sociales de l'histoire véhiculées par les médias et diffusées dans les encyclopédies sont peut-être l'une des meilleures démonstrations qu'il reste beaucoup à faire pour décoloniser la connaissance. Dans ces récits le «Nord» tend à être représentée comme le moteur de l'histoire tandis que le «Sud» reste dans l'oubli.

Cet article examine les résultats de deux études menées auprès d'étudiants au Mozambique et au Portugal. Les représentations sur l'histoire nationale (étude 1) et le processus de colonisation et ses conséquences (Étude 2) sont analysés. Convergences et divergences entre les résultats obtenus dans les deux pays sont discutées en tenant compte du rôle des identités sociales dans la structuration de la mémoire collective.

\section{INDEX}

Mots-clés: Mémoire sociale, représentations sociales, colonisation, décolonisation, Mozambique, Portugal

Keywords: Social memory, social representations, colonization, decolonization

Palavras-chave: Memória social, representações sociais, colonização, descolonização, Moçambique 


\section{AUTHORS}

\section{ROSA CABECINHAS}

CECS, Universidade do Minho

cabecinhas@ics.uminho.pt

\section{JOÃO FEIJÓ}

CIES, Instituto Superior Monitor, Maputo

joaofeijo@hotmail.com 